\title{
Anàlisi toponímica de l'Horta de València. Integració dels enfocaments clàssic i crític per a la reconstitució i revaloració del seu paisatge
}

\author{
Joan Carles Membrado-Tena \\ Emilio Iranzo García \\ Universitat de València. Departament de Geografia \\ joan.membrado@uv.es \\ emilio.iranzo-garcia@uv.es
}

\section{Resum}

La comarca de l'Horta de València, la més poblada del País Valencià, rep aquest nom perquè fins a principis del segle XX la seua economia es basava en la seua riquíssima horta ('terra de regadiu'). A partir de l'estudi dels topònims dels seus nuclis urbans (on l'horta ha estat eradicada) es reconstitueix virtualment el paisatge cultural hortícola perdut en les últimes dècades per a donar a conèixer a la ciutadania i així conscienciar-la del valor patrimonial d'aquest paisatge cultural de l'aigua desaparegut, i també per a revalorar el que sobreviu d'horta encara. Es porta a terme una anàlisi toponímica dels nuclis habitats de la comarca: d'una banda, seguint la metodologia clàssica de recol-lecció de noms de lloc i explicació del seu origen i semàntica; de l'altra, des de l'enfocament crític que estudia l'aspecte ideològic $\mathrm{i}$ identitari que enclou la toponímia. Tots dos enfocaments poden integrar-se per a obtenir una anàlisi toponímica més complexa.

Paraules clau: Horta de València; toponímia; paisatge; horta (regadiu)

Resumen. Análisis toponímico de la Horta de València. Integración de los enfoques clásico y crítico para la reconstitución y revalorización de su paisaje

La comarca de la Horta de València, la más poblada del País Valenciano, recibe este nombre porque hasta principios del siglo XX su economía se basaba en su riquísima horta o huerta ('tierra de regadío'). A partir del estudio de los topónimos de sus núcleos urbanos (donde la huerta ha sido erradicada) se reconstituye virtualmente el paisaje cultural hortícola perdido en las últimas décadas para dárselo a conocer a la ciudadanía y así concienciarla del valor patrimonial de este paisaje cultural del agua desaparecido, y también para revalorizar lo que de huerta sobrevive todavía. Se lleva a cabo un análisis toponímico de los núcleos habitados de la comarca: por un lado, siguiendo la metodología clásica de recolección de nombres de lugar y explicación de su origen y semántica; por otro, desde el enfoque crítico que estudia el aspecto ideológico e identitario que encierra la toponimia. Ambos enfoques pueden integrarse para obtener un análisis toponímico más complejo.

Palabras clave: Horta de València; toponimia; paisaje; huerta (regadío) 
Résumé. Analyse toponymique de l'Horta de Valence (Espagne). Intégration des approches classique et critique pour la reconstruction et la valorisation de son paysage

L'Horta de Valence, la comarque la plus peuplée du Pays Valencien (País Valencià, à l'est de l'Espagne), est ainsi nommée parce jusqu'au début du XXe siècle son économie était basée sur sa riche horta ou huerta (ensemble de terres irriguées). À partir de l'analyse de la toponymie de ses villes et villages (où la plupart des terres irriguées ont été remplacées par la zone urbaine), nous tentons une reconstitution virtuelle du paysage culturel de l'Horta (qui a en grande partie disparu au cours des dernières décennies) avec l'intention de rendre ses citoyens conscients de la valeur patrimoniale de ce paysage culturel, et de mettre en valeur l'horta qui survit encore. Nous effectuons aussi une analyse des noms de lieu de l'Horta, selon la méthodologie classique de collecte des toponymes suivie d'une explication de leur origine et de leur sémantique et en même temps selon une approche critique étudiant les aspects idéologiques et identitaires de la toponymie. Ces deux approches peuvent être intégrées afin d'obtenir une analyse plus complexe des noms de lieu.

Mots-clés: l'Horta de València; toponymie; paysage; horta (terre irriguée)

Abstract. Analysis of place names in l'Horta de València (Spain). Integration of the classical and the critical approaches for the reconstruction and enhancement of its landscape

L'Horta de València, the most populated district in the land of València or Valencian Country (Pais Valencià, in eastern Spain), is so named because until the early twentieth century its economy was based on its rich horta or huerta (irrigated land). From the analysis of its towns' and villages' place names (referring to areas where horta has been suppressed) we attempt a virtual reconstitution of the cultural landscape of l'Horta (which has for the most part disappeared in the last decades). Thus, we intend to make its citizens aware of the heritage value of this cultural landscape, and also to enhance what still survives of it. We carry out an analysis of l'Horta place names, following the classic methodology of collecting place names and explaining their origin and semantics, but also following the critical approach that studies the ideological and identity aspects behind place names. Both approaches can be integrated to obtain a more complex analysis of place names.

Keywords: l'Horta de València; toponymy; landscape; horta (irrigated land)

\section{Sumari}

1. Introducció

2. Objectius

3. Antecedents i estat de la qüestió

4. Cas d'estudi i metodologia

5. Resultats
6. Discussió. Integració de les anàlisis toponímiques clàssica i crítica

7. Consideracions finals. Plausibilitat de l'anàlisi toponímica

Referències bibliogràfiques 
Stat rosa pristina nomine, nomina nuda tenemus.

Umberto Eco

\section{Introducció}

Les planes mediterrànies, com ara l'Horta de València, albergaren fins a mitjan segle XX una fecunda agricultura de regadiu, el paisatge de la qual va fascinar durant segles els viatgers nord-europeus que les visitaven. Les hortes mediterrànies són paisatges culturals — creacions humanes - fruit i testimoni d'una activitat agrícola plurisecular. Tanmateix, el creixement urbanístic descontrolat de les ciutats mediterrànies al llarg de les darreres dècades ha provocat la progressiva disminució dels espais agraris, i la degradació dels paisatges hortícoles romanents. Entre els anys 1997 i 2007, l'expansió de la ciutat difusa va propiciar la reducció i l'abandonament de l'espai agrari al voltant de les ciutats mediterrànies espanyoles a una velocitat mai vista fins llavors (Membrado-Tena, 2015a: 262-264). Això ha coincidit en el temps amb una progressiva conscienciació ambiental entre la població urbana, gràcies al paper de determinats col-lectius defensors de la preservació dels paisatges culturals que han tingut la capacitat de difondre a través dels mitjans de comunicació les seues idees conservacionistes (Nogué i De San Eugenio, 2011: 30). És difícilment factible, a hores d'ara, revertir el paisatge perdut de les hortes mediterrànies; més viable és mantenir allò que encara no n'ha desaparegut, però està en risc de fer-ho per la manca de viabilitat econòmica i de relleu generacional entre els llauradors. Amb el present article volem contribuir a aquesta tasca mitjançant la conscienciació entre la població urbana del valor cultural, identitari, mediambiental i econòmic dels paisatges hortícoles, en particular, i dels paisatges culturals de caire agrari, en general.

D'una banda, emfatitzem que un dels elements patrimonials millor preservats del paisatge hortícola - $\mathrm{i}$, en general, de qualsevol altre tipus de paisatge agrícola - és precisament la toponímia. Les formes lingüístiques arcaïtzants dels noms de lloc, fossilitzades en el temps, converteixen la toponímia en un excepcional descriptor diacrònic del paisatge. D'altra banda, remarquem el paper de la toponímia — en tant que element cultural i identitari- a l'hora de conscienciar la població del valor d'aquest paisatge i, per tant, de la necessitat d'aturar la degradació i la destrucció dels espais agraris supervivents.

\section{Objectius}

El primer objectiu d'aquest article és analitzar l'origen semàntic dels noms dels nuclis urbans de l'Horta de València, que són els llocs on normalment el paisatge agrari ha desaparegut o està mig esborrat. El segon objectiu és reconstituir el paisatge perdut de l'Horta de València a partir de l'anterior anàlisi toponímica. Un tercer i últim objectiu és divulgar — donar a conèixer- entre la ciutadania la semàntica dels noms dels municipis on resideixen, per tal de conscienciar-la 
del valor excepcional del paisatge ja desaparegut i de la necessitat de protegir allò que en resta.

Per a dur a terme el primer objectiu ens basem en una anàlisi toponímica clàssica, fonamentada en la recol-lecció i l'estudi etimològic dels noms de lloc. Per al segon, mostrem els resultats obtinguts en una taula, en un mapa i en el text de l'apartat de resultats. Per al tercer objectiu partim d'una anàlisi toponímica crítica, mitjançant la qual posem de relleu el valor identitari dels noms de lloc i la utilitat d'aquests en la reconstitució i defensa del patrimoni paisatgístic. Abans d'explicar amb més detall la metodologia convé referir-nos als dos enfocaments metodològics propis de l'anàlisi toponímica i al lligam entre el paisatge i la toponímia.

\section{Antecedents i estat de la qüestió}

\subsection{La ciència toponimica $i$ els diversos enfocaments metodològics d'anàlisi}

La toponímia, branca de l'onomàstica que estudia els noms de lloc, és una disciplina de síntesi en la qual convergeixen diferents camps de coneixement que interactuen de manera complementària (Tort i Sancho, 2014: 1987). L'anàlisi semàntica dels topònims es basa en tres ciències auxiliars principals: història, geografia i lingüística, i dins d'aquesta última especialment la dialectologia i la fonètica (Poirier, 1965). D’altres autors destaquen més la vessant sociològica i filosòfica de la toponímia, tot afirmant que la creació al llarg de la història de noms per a designar llocs ens permet comprendre millor les preocupacions reals i místiques de les persones que els van crear (Dauzat, 1971: 9).

Dorion (1984) considera que els estudis toponímics poden emparentar-se amb la geografia, història, lingüística, sociolingüística, psicolingüística i psicologia social. Els trets geogràfics d'un topònim poden desvelar-ne l'origen semàntic; la història pot ajudar a entendre un topònim en un context social determinat; l'anàlisi morfològica i semàntica d'un topònim, tant el seu origen com l'evolució, s'emparenta amb la lingüística (semàntica, morfologia); l'anàlisi de grans conjunts de topònims està vinculada a la sociolingüística; la psicolingüística destaca els topònims en tant que signes lingüístics i com a tal d'interès per a la semiòtica; la psicologia social estudia els topònims en tant que expressions d'una percepció d'un lloc. Querol (1995: 65) defensa que la casuística que enclou la toponímia és tan variada que hi ha infinites maneres d'abordar-la, sense que cap haja de prevaler sobre la resta. A part dels camps de coneixement proposats per Dorion, podem afegir-ne d'altres tan aparentment allunyats de la toponímia com ara la teledetecció (Membrado-Tena, 2015b).

El mètode clàssic d'anàlisi toponímica se centra en la recol-lecció de noms de lloc per a detallar-ne l'origen i la semàntica, per la qual cosa és fonamental acudir a ciències auxiliars com ara la geografia, la història i la lingüística (Tort, 2001). Tanmateix, més enllà del significat geogràfic o de l'origen històrico-lingüístic, l'acte de toponimitzar va lligat a un procés socioespacial que és fruit del context ideològic i identitari (Zelinsky, 1997: 465; Withers, 2000; Kearns i Berg, 2002; Rose-Redwood et al., 2010: 456). 
Des de fa algunes dècades són nombrosos els treballs que estudien la toponímia des d'una perspectiva critica - seguint la terminologia anglosaxona-i que se centra en aspectes socioespacials. Dins l'escola toponímica catalana no són pocs els autors que, des de fa dècades, teoritzen sobre el vessant ideològic i identitari de la toponímia. Coromines (1965: 7) lligava l'interès per l'estudi de la toponímia a la curiositat inherent de l'ésser humà, que és particularment intensa en el cas dels noms de llocs, ja que aquests posseeixen una forta càrrega identitària per a les persones amb qui entren en contacte cada dia. Moreu-Rey (1995: 47) distingeix entre l'etimologia, que estudia l'origen i la filiació lingüística d'un nom, i l'etiologia, que estudia les motivacions que han originat un topònim (Terrado, 1994: 59-60). Les motivacions socials que permeten la creació d'un topònim depenen del grup humà que l'accepta o el rebutja com a identificador d'un lloc, i aquesta tria està lligada a la mentalitat social i als valors imperants en cada època (Terrado, 2007: 384).

La perspectiva ideològico-identitària de la toponímia deriva del fet que els noms de lloc, allotjats en contextos culturals més amplis, evoquen un ampli espectre d'emocions que les persones interpreten socialment de diferent manera (Thornton, 1997; Davidson et al., 2005; Kearney i Bradley, 2009). La toponímia reforça la identitat d'un lloc en tant que símbols que designen i defineixen un lloc, i que enforteixen els llaços emocionals amb l'espai (Jordan, 2012: 125129). Els topònims han de ser entesos com a part d'un procés socioespacial dinàmic que està darrere de la identificació de les persones amb un passat que, en forma d'història i memòria, proporciona un vincle afectiu per a la vida i la identitat de les persones en el present (Fuchs, 2015: 13).

Els estudis toponímics que prioritzen l'aspecte socioespacial sobre l'etimològic — el paradigma crític sobre el clàssic — se centren principalment en àrees que van ser colonitzades (com ara Amèrica i Àfrica) o dominades per polítiques totalitàries (com ara les de l'Europa d'entreguerres). Les potències colonials o els règims autoritaris hi van crear o transformar determinada toponímia com un mecanisme per tal de consolidar el nou ordre polític dominant. Amb la derrota i/o retirada de la metròpoli o del règim, els nous governants van reemplaçar-hi aquells topònims per altres que reivindicaven la nova ideologia (més o menys democràtica, segons els casos) i la identitat pròpia (cultura i llengua).

Un exemple paradigmàtic de la perspectiva ideològica i identitària de la toponímia el trobem a l'Espanya franquista (1936/9-1977): «Avenida del Generalísimo» era el nom de les dues grans artèries urbanes de Madrid i de Barcelona (actuals Paseo de la Castellana i Avinguda Diagonal, respectivament). La majoria dels topònims franquistes han estat substituïts en la democràcia, $i$ en els territoris de llengua gallega, basca o catalana s'ha recuperat el nom dels municipis en la llengua pròpia, l'ús oficial de la qual havia estat bandejat durant la dictadura (Membrado-Tena, 2012 i 2014). D'altres exemples els trobem a Alemanya, on Hitler havia previst canviar el nom a Berlín per a dir-li Welthauptstadt Germania (Germania Capital Mundial), i on, sota el govern de la República Democràtica Alemanya, la ciutat saxona de Chemnitz va ser anomenada Karl-Marx-Stadt entre 1953 i 1990; o a Itàlia, on després de la caiguda 
del règim feixista de Mussolini, la ciutat de Mussolinia di Sardegna va passar a dir-se Arborea, i la de Littoria (de fascio littorio, el símbol feixista) va canviar el seu nom pel de Latina; o a la URSS, on Sant Petersburg esdevingué Leningrad (1924-1991) i la ciutat tàrtara de Sary Su o Tsaritsyn Stalingrad (1929-1961) i després Volgograd. A vegades, no és necessària la caiguda d'un règim perquè es done aquesta circumstància: el pic més alt dels EUA, anomenat entre 1896 i 2015 McKinley (pel president homònim), es diu des de 2015 Delani, nom tradicional d'aquest pic en llengua Tanaina (idioma d'Alaska).

Alguns dels nous estudis toponímics crítics també tracten aspectes de raça i gènere (Berg i Kearns, 1996; Alderman i Inwood, 2013), ja que el domini polític tradicional dels homes de raça blanca ha desterrat de la toponímia urbana els noms de dones, en general, i de persones afroamericanes, en particular (o almenys els ha mantingut com relativament infreqüents). També són estudiats sota el mateix enfocament altres fenòmens recents com ara la mercantilització toponímica (Mitchelson et al., 2007; Light i Young, 2015): cada vegada són més els noms de lloc els drets dels quals són comprats i venuts com a mercaderia, ja que són una forma de poder simbòlic que crea distinció social entre les elits i el populatxo i que pot transformar-se en capital simbòlic (Bourdieu, 1991; Raento i Douglass, 2001; Alderman, 2008; Rose-Redwood, 2008).

Cal assenyalar que la imatge de poder que generen els topònims ha exercit secularment un paper notable en l'economia política de promoció d'un lloc. En temps romans, per exemple, es van fundar colònies els topònims de les quals pretenien seduir els colons perquè acudiren a poblar-les: PLASENTIA, 'lloc agradable' (d'on deriven Plasencia i Piacenza); FlorentiA, 'fertil' (Florència); o VALENTiA, 'lloc fort, vigorós' (d'on deriven València, Valence, Valença i Valenza). Moltes de les urbanitzacions construïdes durant les últimes dècades ignoren la toponímia tradicional i són batejades pels seus promotors amb un nom suposadament atraient i seductor per al mercat (Panorama, Costamar, Costabella, El Pinar, El Jardí, etc.).

Alguns autors consideren que el creixent pes de l'enfocament toponímic crític pot afeblir l'interès per l'anàlisi d'aquells territoris on la majoria dels topònims no es van imposar mitjançant polítiques ideològico-identitàries (Whatmore, 2002: 533). Tanmateix, cal dir que fins i tot els topònims medievals pragmàtics, que aparentment es limiten a descriure els elements del paisatge, estan lligats a la ideologia dominant d'aquell moment, ja que el paisatge -i els noms triats per les persones per a descriure'l — no és més que una manifestació col-lectiva de la ideologia pròpia del moment històric en què es forja (Terrado, 2007: 384; Di Giminiani i Fonck, 2015: 8).

\subsection{Toponimia i paisatge}

El geògraf nord-americà Carl Sauer (1956: 289-291), molt avançat i influent en l'estudi dels paisatges culturals, considerava que els topònims eren la quarta dimensió - la temporal — de la geografia, per tal com l'anàlisi dels topònims contribuïa a la reconstrucció dels paisatges històrics. En la mateixa línia, Riesco 
(2010: 22) creu que l'anàlisi dels noms de lloc és la manera de comprendre l'evolució d'un paisatge secular que ja no hi és.

La toponímia, en efecte, rescata el passat mitjançant les diferents capes i estrats de noms acumulats al llarg de la història (Algeo i Algeo: 2000; Grimalt et al., 2009; Georgiou, 2010; Steenkamp, J., 2015). Això es deu al fet que els noms de lloc són notablement conservadors: d'una banda, la seua evolució morfològica sovint s'atura per molt que els noms comuns de la mateixa llengua continuen evolucionant; de l'altra, molts sobreviuen a l'extinció local de la llengua en què van ser creats (com va passar amb l'àrab a València), perquè continuen sent útils per a designar un enclavament específic i diferent de la resta de llocs, encara que manquen de significat lèxic en la nova llengua del lloc. Els topònims no funcionen, per tant, com a unitats lèxiques normals. Posseeixen un significat referencial i per això no necessiten evolucionar d'acord amb la morfologia de la llengua ni ser substituïts en cas que aquesta llengua siga suplantada per una altra (Raper, 2011: 7-8). Gràcies a aquest mecanisme de fossilització els noms de llocs esdevenen una font inesgotable d'informació històrica que possibilita la reconstrucció virtual d'un paisatge ja desaparegut.

La definició que des de la geografia s'ofereix del concepte de paisatge és complexa, diversa i canviant: primer va ser descrit com un element natural; després com un d'humanitzat; finalment s'arribà a una definició sintètica, en què es combinaven aspectes físics i humans (Tesser, 2000: 24). Però el paisatge no és només allò visible, sinó també allò que es percep. I és precisament en la percepció que rau la diferència essencial entre territori i paisatge: el primer és percebut a través dels sentits (especialment la vista) per les persones, que són les que permeten l'existència del segon després d'aprehendre el primer (Zubelzu i Allende, 2015: 30-31). Hi ha autors que destaquen el paper del caràcter en la definició del paisatge, entenent aquest com l'empremta que secularment ha imprès la societat sobre la naturalesa, i que dóna sentit de lloc a cada territori (Mata, 2014: 12).

Com a definició transversal que integra les tesis anteriors cal referir-se a la publicada al Conveni Europeu del Paisatge (Consell d'Europa, 2000), segons la qual paisatge "fa referència a una àrea, tal com la percebi la gent, el caràcter de la qual és resultat de l'acció i la interacció de factors naturals i/o humans». Aquesta definició sintètica i holística, que estén la qüestió paisatgística a tot el territori i que integra allò material i allò immaterial, engloba explícitament tres notables trets propis de la noció de paisatge: el component territorial o paisatge-regió, la percepció o paisatge-imatge i el caràcter o paisatge-memòria; de manera implícita aquesta definició inclou a més dues nocions més de paisatge: la de paisatge-recurs, quan la preservació del seu caràcter pot generar beneficis econòmics, i la de paisatge-indicador, en què se n'avalua la qualitat (allò que li dóna caràcter i el diferencia de la resta de paisatges). Tot seguit desglossem la funció que exerceixen els noms de lloc en cadascuna d'aquestes nocions descrites per Claudio Tesser (2000).

En el paisatge-regió les persones s'adapten al medi i a través de l'explotació dels recursos naturals conformen un paisatge, el qual, una volta configurat, 
no és estàtic, sinó que canvia com a conseqüència de l'avanç social (Iranzo, 2009; Nogué i De San Eugenio, 2011). Al llarg del dilatat procés cultural de conformació d'un paisatge, els seus creadors tenen la necessitat de donar nom a cadascun dels elements que han intervingut en la configuració del paisatge-regió. Els topònims designen característiques espacials, particularment de tipus natural (aigua, vegetació, relleu, recursos minerals, tipus de sòl, morfologia), però també puntualitzen el tipus d'assentament, l'ús del sòl i l'economia, o els fets històrics. Els noms de lloc descriuen allò que és important des del punt de vista de l'aprofitament humà, i no en totes les cultures és important la mateixa cosa (Jordan, 2012: 125): per a les cultures agrícoles de clima mediterrani l'aprofitament hidràulic és vital, però per a les ramaderes interessa més el tipus de coberta vegetal.

El paisatge-imatge evoca la percepció i la interpretació del territori que efectuen les persones que l'observen. La interpretació depèn de l'experiència vital anterior de l'observador, que es va configurant a través de l'aprenentatge individual, però també del context cultural. Així, davant d'una mateixa realitat territorial el paisatge percebut pot ser diferent, igual que les actituds davant d'aquest o les valoracions que se'n fan. El paisatge-imatge, per tant, està carregat de subjectivitat (Mata, 2008: 157). Aquesta noció queda ben il.lustrada amb les percepcions radicalment diferents que de l'horta valenciana presentaven el conservador Teodor Llorente - que enaltia el bucòlic paisatge hortolà- i el republicà Vicent Blasco Ibáñez — que en mostrava una imatge descarnada i tràgica- (Domínguez, 2014; 68-71). En el paisatge percebut l'ús dels topònims és també subjectiu: depèn de la significativitat d'aquests per a la persona observadora.

El paisatge-recurs és aquell que la població percep com a element destinat a satisfer una necessitat. És un recurs en la mesura que és utilitzable per la societat. El paisatge pot ser considerat com un objecte de consum cultural, ecològic, mediambiental i social, fet que implica una protecció, gestió i ordenació per a preservar-lo (Mata, 2014: 11; Zubelzu i Allende, 2015: 32). Aquesta preservació contribueix a crear ocupació i beneficia el turisme, fet que redunda en més ocupació i més beneficis econòmics. El fet que hi haja una concepció del paisatge com a recurs porta a la seua consideració com a patrimoni (Higueras, 2009; Gómez-Mendoza, 2013) i, en tant que patrimoni, cal gestionar el paisatge per la seua singularitat, rellevància, valor i perdurabilitat (Iranzo, 2009). Quant a la funció dels topònims, aquesta és merament utilitària: es limita a donar nom a llocs significatius que formen part d'un sistema general d'orientació espacial.

El paisatge-indicador se centra en l'avaluació del paisatge. Es tracta d'una aproximació més o menys quantitativa que pretén determinar els trets del seu caràcter: allò que el fa diferent a altres (Mata, 2008: 159). Aborda alhora temes diversos com ara els problemes ecològics i institucionals, o les tensions i els conflictes que es poden presentar en un territori (Tesser, 2000: 25). La funció dels topònims, com en la noció anterior, és utilitària.

Finalment, el paisatge-memòria correspon a l'espai del record, de les vivències, dels afectes; a l'espai on s'ha forjat la història d'un lloc i on evolucionen els 
elements que constitueixen l'imaginari col-lectiu. El paisatge-memòria explica la formació, la consolidació i el manteniment d'identitats territorials (Nogué, 2007: 374). És considerat com un registre dels mètodes i pràctiques socials, polítiques i culturals del passat, on encara queda prou patrimoni històric $\mathrm{i}$ cultural amb el qual traslladar la memòria a altres societats pretèrites que van ocupar el mateix espai (Tesser, 2000: 24-25). Entre les principals evidències patrimonials per a rescatar la memòria d'un paisatge es troba la toponímia.

\section{Cas d'estudi i metodologia}

El cas d'estudi analitzat en aquest article és el de l'Horta de València, paradigma de les planes mediterrànies amb un ric paisatge agrari basat en l'aprofitament hidràulic de les escasses aigües disponibles. Amb $621 \mathrm{~km}^{2}$ i més d'1,5 milions d'habitants (vora $2.500 \mathrm{hab} / \mathrm{km}^{2}$ ), l'Horta de València és la comarca més poblada del País Valencià (figura 1) i l'única que hi ha tingut mai reconeixement oficial, gràcies a les competències transferides (1986-1999) per a la planificació territorial metropolitana (Membrado-Tena, 2016: 357).

En aquest article l'anàlisi toponímica es restringeix als nuclis urbans, ja que és als pobles i ciutats que el paisatge hortolà ha desaparegut o és residual, $\mathrm{i}$ on queda poc més que els topònims per a recordar-lo. A banda, els topònims urbans són noms amb un notable fonament històric, estan ben documentats i, per la seua rellevància, han estat estudiats pels especialistes en la matèria (Tort, 2000).

Figura 1. Localització de l'Horta de València al País Valencià
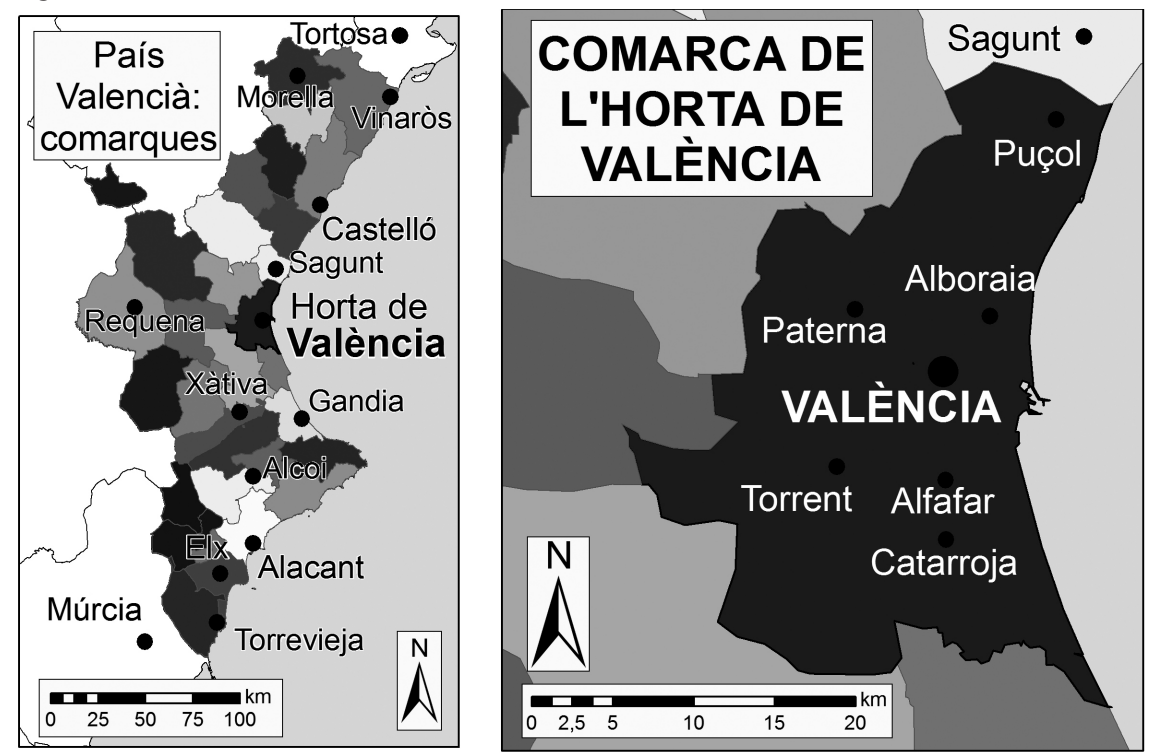

Font: elaboració pròpia 
Hi analitzem 82 noms de lloc, dels quals 47 corresponen a municipis (hi ha només 44 municipis, però 3 d'aquests presenten dos elements semàntics rellevants), i la resta a nuclis pertanyents a l'ampli terme de València.

Quant a la metodologia seguida per a fer l'anàlisi toponímica clàssica hem creat onze categories temàtiques, de les quals l'orografia, la hidrografia, la toponímia litoral i la vegetació responen a trets físics, mentre que la defensa, el poblament (subdividit en dispers i concentrat), la xarxa viària (subdividida en camins i hostals) i l'agricultura (subdividida en conreus $\mathrm{i}$ regadiu) presenten trets propis de la geografia humana. Aquesta classificació temàtica l'hem creada d'acord amb la taxonomia que solen fer servir els especialistes en toponímia, tot i que per l'abundància i la rellevància dels topònims agraris hem creat alguns subgrups específics a banda. Quant a l'origen històrico-lingüístic trobem tres procedències: llatí i llatí tardà (s. II a. C.-s. VIII), àrab i amazic (s. VIII-s. XIII) i català o valencià (del s. XIII ençà).

Pel que fa a la metodologia seguida per a fer l'anàlisi toponímica crítica, partim dels resultats obtinguts de l'anàlisi clàssica per a, a continuació — seguint els raonaments teòrics que han fet diversos autors sobre la incidència socioespacial que condiciona la creació de topònims—, aplicar-la al nostre cas d'estudi.

\section{Resultats}

\subsection{Anàlisi toponímica clàssica}

Hem analitzat el contingut semàntic dels topònims que actualment designen nuclis urbans a l'Horta, seguint la classificació temàtica descrita a la metodologia.

Quant a l'orografia, la major part de l'Horta s'assenta sobre una franja alluvial entre la mar Mediterrània i els raiguers més orientals del Sistema Ibèric. A només $5 \mathrm{~km}$ de la ciutat de València es troba Burjassot, topònim àrab que pot traduir-se per 'torre de l'alteró' (Barceló, 2010: 78). El topònim Godella sembla derivar del diminutiu femení del llatí cos, COTIS, 'pedra, roca', i podria equivaler a 'pedregar' o 'rocam'. Aquest significat escau amb el fet que al municipi de Godella es trobe la pedrera històrica de la ciutat de València, a partir de la qual es construïren els principals monuments gòtics de la ciutat. Godella sembla un parònim de Cotella, topònim eivissenc (no sonoritzat) amb el mateix origen lingüístic i contingut semàntic (Ribes, 2005: 33). El topònim Rocafort - poble veí de Godella i també pedregós - posseeix un contingut semàntic transparent en català: roca fort (a); l'adjectiu masculí s'explica perquè, en un estadi del català anterior a l'actual, certs adjectius que avui tenen flexions de gènere llavors no en tenien. El Puig de Santa Maria és un altre orònim transparent. Aquest turó o puig fou una indret clau en la conquesta cristiana de València, en ser el més proper a la ciutat —a només $15 \mathrm{~km}$ — venint des de Catalunya i Aragó. Amb la victòria de les tropes cristianes el 1237 en la batalla del Puig, Jaume I hi establí la base d'operacions per al setge i conquesta de la ciutat de València, que capitulà només un any després. El topònim preromà Carpesa sembla derivar de Kar, 'penya', més $p$, 'peu', més el sufix -esa, i voldria 
dir 'lloc al peu de les penyes'. Aquest antiquíssim topònim fa referència a un poble que es troba ben a prop (al peu) de les penyes de Rocafort i Godella. Alfafar procedeix del plural àrab al-hufar, 'forats', 'clots' (Barceló, 2010: 51) i es refereix per tant a un orònim còncau, com també ho és Foios, del llatí tardà *FOVEOS, 'clots, forats', hoyos en castellà (Coromines, 1989-1997, IV: 237).

Pel que fa a la hidrografia, Borbotó sembla derivar d'un encreuament entre borbollar i brotar (Segura, 2014: 38) i es refereix probablement a un ullal. Puçol, del llatí tardà *PUTEOLO, 'pouet' (Coromines, 1989-1997, vi: 286), probablement també es refereix, en sentit figurat, a un altre ullal, ja que les surgències abunden al terme de Puçol, com també als municipis parònims de Pozuel del Campo (Aragó), Pozuelo de Alarcón (Madrid) i Pozzuoli (prop de Nàpols i amb surgències geotermals). Els topònims de la Fonteta (de Sant Lluís) i de la Font (d'en Corts) són transparents, mentre que Marxalenes deriva de l'àrab marj al-ain, 'la marjal de la font' (Coromines, 1989-1997, III: 91). El topònim transparent Torrent es refereix al torrent que envolta aquesta localitat pel seu flanc oest i nord, mentre que Silla sembla procedir de l'àrab as-Sila, 'torrent' (Barceló, 2010: 56).

Quant a la toponímia litoral, els dipòsits al-luvials del barranc de Torrent van formar una petita punta o cap dins l'Albufera de València, que és l'origen últim del topònim Catarroja, on el lexema cata deriva de CAPITA, 'cap, punta' (Barceló, 2010: 42), mentre que roja obeeix al color tèrbol de les aigües. El topònim Cap de França es diu així per un cap poc prominent que es troba al nord (mirant cap a França) del Poble Nou de la Mar (actual Cabanyal) (Sanchis Pallarés, 2009: 106), mentre que el topònim la Punta (antigament la Punta d'en Silvestre) deriva del fet que aquest poble es trobava sobre una antiga llengua de terra que penetrava dins l'Albufera (Carmona, 2002: 25). El Saler es refereix a una salina, la sal de la qual era transportada en barca fins al poble actual del Saler (uns $6 \mathrm{~km}$ al nord de l'esmentada salina), des d'on era després duta per via terrestre a la ciutat de València (Rosselló, 1987: 126). Els orígens de Natzaret estan lligats a un establiment portuari - anomenat lazzareto o llatzeret (i després confós amb el Natzaret dels evangelis)—, on les persones que hi arribaven en vaixell passaven la quarantena (Teixidor, 2004: 227). El Grau, del llatí GRADUS, és el nom tradicional del port de València. La falta de calat a la costa del golf de València obligà a fer un "grau» (graó artificial), ja des d'època medieval, per a facilitar la càrrega i descàrrega de les mercaderies que entraven i eixien per via marítima (Rosselló, 2004: 16). El poble albuferenc del Perellonet (terme de València) sembla un diminutiu del veí Perelló (terme de Sueca). Aquest darrer és probable que derive d'una forma masculina i diminutiva de peira, en referència a una pedra que mesurava l'altura de l'aigua de l'Albufera (Sanchis Ibor, 2000: 438-439).

Entre els topònims relacionats amb el poblament concentrat cal esmentar Alfara, de l'àrab al-hara, 'barri' (Barceló, 2010: 66). Pel que fa al Cabanyal, el seu origen es remunta al segle XIII, quan un grup de pescadors s'hi establiren $\mathrm{i}$ començaren l'edificació en primera línia de platja de barraques o cabanyes, que acabaren donant nom al poble del Cabanyal, citat per primera vegada el 1422 
(Sanchis Pallarés, 2009: 16). Parònim de Cabanyal és Campanar, que deriva del llatí CAPANNAR, 'cabanyal' i que fou transformat pels cristians catalanoparlants en Campanar (Coromines, 1989-1997, III: 216). La Pobla, Poblenou, Llocnou i les Cases (de Bàrcena) són topònims transparents que indiquen una agrupació de cases.

Els antropònims descriuen un poblament dispers on els propietaris rurals que donen nom als llocs posseïen una casa de camp i els terrenys agrícoles adjacents. Entre els d'origen llatí cal citar Paterna, derivat de PATERNUS, -A, 'relatiu al pare' (Coromines, 1989-1997, vI: 169). Pel que fa a Meliana i Picassent, derivarien de sengles propietaris d'una vila tardoromana o fundus: la VILLA AEMILIANA, propietat d'AEMILIUS, i el FUNDUS *PICATIANUS, pertanyent a un tal *Picatius o *PaCATIUS (ibid., vI: 223). Els antropònims àrabs es corresponen normalment amb noms d'alqueries, molts dels quals comencen per Beni-, derivat d'ibn, 'família, clan': Beniparrell, Benimaclet, Benimàmet, Benifaraig, Benicalap, Benimassot (actualment anomenada el Forn d'Alcedo), Beniferri, Benetússer, Sedaví (s. XIII Beniçidavi) i Vinalesa (s. XIII Benivolesar) (Barceló, 2010: 92-106). Albuixec també és un antropònim àrab, derivat d'Abu, 'pare' (ibid.: 98). Entre els antropònims catalans cal citar Montcada, derivat del noble i militar Pere I de Montcada, que prengué part en la conquesta de València i que fou recompensat amb la torre dita, per aquest motiu de Montcada, conquerida per Jaume I el 1235. El topònim Orriols deriva de Pere d'Orriols, canonge de la catedral valentina durant el segle XIV (Diéguez, 1988: 115). La Venta d'Emperador (oficialment Emperador) va ser adquirida a mitjan segle XVIII pel comerciant Agustí Emperador (Gil Olcina, 2003: 160). El nom de l'alqueria de Mirambell (abans Miralbell) sembla ser un antropònim derivat del llinatge d'algun cavaller català (Coromines, 1989-1997, v: 279), mentre que el de la veïna alqueria de Bonrepòs més aviat seria un exemple de topònim propagandístic o mercantilitzat, ja que descriu un lloc agradable i seductor per a atraure-hi colons (ibid., III: 64). El topònim Pinedo, citat per primera vegada al segle XIX, deriva del cognom d'un propietari rural de la zona; segons la documentació del segle XVI aquest llogaret es corresponia amb el desaparegut Rafal dels Tortosins (Sanchis Ibor, 2000: 436). Pinedo també és conegut amb el nom de Creu de la Conca, sent la conca probablement un antic espai llacunar o d'aiguamoll (Rosselló, 1987: 128), mentre que la creu es refereix a la creu gòtica que allà es troba.

Altres topònims (no antropònims) que descriuen poblament dispers són Museros, que sembla procedir del llatí tardà MANSUARIOS, 'masovers', 'maseros', amb una complexa evolució fonètica influïda per l'àrab (Coromines, 19891997, v: 430). Picanya, d'origen dubtós, podria derivar d'una forma llatina tardana *PAGANEA, 'lloc de pagans o de pagesos' (ibid., vI: 222). Mauella prové de l'àrab niuala, 'barraca, casa de pagès' (Barceló, 2010: 64).

Pel que fa a l'agricultura, el topònim àrab Rafelbunyol estaria relacionat amb rahal, 'explotació rústica en secà' i amb -bunyol, que deriva de bunyul, 'vinya' i, per tant, seria 'el secà (o el mas) de la vinya' (Barceló, 2010: 70). Aldaia deriva de l'àrab al-Daia, 'la finca, l'hort' (ibid.: 65) (cf. Addaia de 
Menorca, Daia d'Oriola). Almàssera prové de l'àrab al-màssara, 'el trull' (ibid.: 85). L'Oliveral és un agrònim de semàntica transparent. Quant al Canyamelar cal dir que cap al segle XV (abans de la petita edat de gel) el regne de València produïa sucre per a Barcelona, com ho testimonien diversos documents, entre els quals un de 1415 que fa referència a algunes possessions de canyamel a les hortes de València i de Castelló (Salicrú, 1995: 189). Potser alguna d'aquestes possessions va donar nom al Canyamelar. La Malva-rosa era una marjal que fou bonificada a mitjan segle XIX pel botànic francès Félix Robillard, que hi plantà diverses espècies vegetals entre les quals destacava el GERANIUM ODORATISSIMUN o malva-rosa (Sanchis Pallarés, 2012). Russafa, de l'àrab ar-rusafa, 'el jardí', deu el nom als jardins d'un palau omeia del segle IX, als afores de la València musulmana. Aquest palau desaparegué, però el jardí es conservà com a lloc d'esbarjo durant l'època andalusina (Corbín, 1995: 25-36) i al seu voltant s'originà una alqueria que és l'origen de Russafa.

Hem creat una categoria semàntica referida específicament als topònims que descriuen el reg agrícola, propi de l'horta, i que es troben a mitjan camí entre la hidronímia i l'agronímia. Dins d'aquest grup cal mencionar Mislata, que podria derivar del llatí tardà MISCULATA, 'barreja, mescla' (Coromines, 1989-1997, v: 288). Aquesta mis(c)lata es referiria a la presa o assut de Mislata on les aigües de la sèquia homònima estan encara barrejades amb les del riu Túria, abans de començar-ne la difluència. Segons Barceló (2010: 82), tanmateix, Mislata provindria de l'àrab Manzil Ata, 'hostal d'Ata'. Alaquàs prové de l'àrab al-aquâs, 'els arcs' (ibid.: 83), per la sèquia de Benàger que havia de travessar el barranc de la Saleta mitjançant un pont amb arcs (avui desaparegut). El topònim Paiporta sembla derivar de PROPE HORTAM, 'prop de l'horta', amb una complexa evolució fonètica per influència aràbiga (Coromines, 1989-1997, VI: 116). Efectivament, l'alqueria de Paiporta es trobava a la vora mateixa de la sèquia i l'horta de Faitanar, sense beneficiar-se'n, però, del reg. Albal sembla derivar de l'àrab al-Bal, 'terra de secà', on Bal faria referència al déu Baal, de manera que Albal serien les terres que no reben més aigua que la pluja que ocasionalment puga enviar aquest déu semític (Corriente, 2008: 58).

Quant a la vegetació trobem Farnals, derivat de FARRAGINALES, 'camps de farratge' (Coromines, 1989-1997, IV: 194); Xirivella, de SILVELla, 'bosquet' (ibid., VIII: 132); i el transparent Palmar, lloc de palmeres o, potser, de palmes (margalló) (Corbín, 1995, 64-65).

Pel que fa a la xarxa de camins, cal ressaltar Quart, del llatí (AD) QUARTUM (MILliarium) (Coromines, 1989-1997, vi: 310), ja que en aquest poble hi devia haver un mil.liari que marcava les quatre milles romanes des de VALENTIA. Albalat (dels Sorells) ve de l'àrab al-Balat, 'el camí empedrat' (Barceló, 2010: 80), i Patraix, antigament Petrair(s), del llatí Petrarius (Coromines, 1989-1997, VI: 171), '(camí) de pedra'. Tots dos pobles es troben ben a prop de la Via Augusta.

Altres topònims relacionats amb la xarxa viària són els hostals, que es trobaven sempre a la vora d'un camí. Tots els topònims valencians que comencen per massa- deriven de manzal (hostal) (ibid., v: 221). A l'Horta en trobem 
Taula 1. Semàntica dels topònims urbans de l'Horta de València

\begin{tabular}{|c|c|c|c|c|c|}
\hline orografia & atribut & Poblament dispers & atribut & camí & atribut \\
\hline Foios & depressió & Benimaclet & alqueria & Albalat (Sorells) & calçada \\
\hline Alfafar & depressió & Benifaraig & alqueria & Patraix & calçada \\
\hline Rocafort & elevació & Benicalap & alqueria & Quart (Poblet) & mil·liari \\
\hline Godella & elevació & Beniferri & alqueria & hostal & atribut \\
\hline el Puig & elevació & Benimàmet & alqueria & Massamagrell & comercial \\
\hline (Burj) assot & elevació & Vinalesa & alqueria & Massanassa & comercial \\
\hline Carpesa & elevació & Albuixec & alqueria & Massalfassar & comercial \\
\hline hidrografia & atribut & Bonrepòs & alqueria & Massarrojos & comercial \\
\hline Puçol & ullal & Benetússer & alqueria & Tavernes (BI.) & comercial \\
\hline Borbotó & ullal & Sedaví & alqueria & Emperador & comercial \\
\hline Torrent & torrent & Benimassot & alqueria & Manises & comercial \\
\hline Silla & torrent & Beniparrell & alqueria & Les Tendetes & comercial \\
\hline La Fonteta & font & Pinedo & alqueria & & \\
\hline Marxalenes & font & Bonrepòs & alqueria & conreu & atribut \\
\hline La Font (Corts) & font & Els Orriols & alqueria & El Canyamelar & conreu \\
\hline litoral & atribut & Mauella & barraca & L'Oliveral & conreu \\
\hline El Saler & salina & Paterna & fundus & (Rafel) bunyol & conreu \\
\hline Catarroja & cap/punta & Picassent & fundus & Aldaia & conreu \\
\hline La Punta & cap/punta & Meliana & fundus & Malva-rosa & conreu \\
\hline Cap (de França) & cap/punta & Picanya & fundus? & Almàssera & industrial \\
\hline Natzaret & portuari & Rafel (bunyol) & $\mathrm{rafal} / \mathrm{mas}$ & Russafa & jardí \\
\hline El Grau & portuari & Museros & masovers & $\underline{\text { regadiu }}$ & atribut \\
\hline \multirow[t]{2}{*}{ El Perellonet } & fita/pedra & Montcada & torre & Mislata & assut \\
\hline & & Pobl. concentrat & atribut & Alaquàs & séquia \\
\hline defensiu & atribut & La Pobla (Farnals) & poble & Albal & secà \\
\hline Alboraia & torre & Poblenou & poble/barri & Paiporta & horta \\
\hline La Torre & torre & El Cabanyal & poble/barri & & \\
\hline Burj (assot) & torre & Cases (Bàrcena) & poble/barri & vegetació & atribut \\
\hline Alcàsser & fortalesa & Alfara (Patriarca) & poble/barri & (Pobla) Farnals & plantes \\
\hline València & fortalesa & Llocnou (Corona) & poble/barri & Xirivella & arbres \\
\hline Castellar & fortalesa & Campanar & poble/barri & El Palmar & arbres \\
\hline
\end{tabular}

Font: Coromines (1989-1997), Barceló et al. (2010).

quatre: Massamagrell, al camí de Barcelona; Massalfassar, al del Puig; Massarrojos, al de Bétera, i Massanassa, al de Xàtiva. El topònim Manises procediria de manàzil, 'hostals' (Barceló, 2010: 82). Les Tendetes eren unes tavernes al camí de Paterna. Tavernes Blanques es refereix a unes botigues situades al camí de Barcelona, junt al qual també hi havia la Venta d'Emperador (avui Emperador). 
Entre els topònims defensius cal citar Burjassot i Alboraia, que deriven respectivament de l'àrab burj as-sudd, 'torre de l'alter', i al-burayyaj, 'la torreta' (ibid.: 78). Alcàsser deriva de l'àrab al-qàssar, 'fortalesa' (ibid.: 77). Castellar derivaria de l'alqueria andalusina de Castelló de l'Albufera (Alcañiz, 1987: 23) i la Torre es va desenvolupar a partir d'una alqueria fortificada del segle XIV (ibid.: 14). El mateix topònim de València deriva del participi present del verb VALERE, 'ser fort, vigorós, saludable', VALENS -ENTIS (Casanova, 2011: 285), i voldria dir 'fortalesa, vigor'.

Hem analitzat 82 topònims urbans (fig. 2), dels quals la meitat són de caire agrari: 7 descriuen conreus; 4, reg; 23, poblament dispers (cases de pagès amb terrenys agrícoles ); i 7, poblament concentrat on també vivien llauradors. No és sorprenent el predomini d'aquest tipus de topònims, ja que els espais agrícoles han actuat com a motor econòmic de les societats mediterrànies fins ben entrat el segle XX. La resta de topònims estudiats descriuen trets orogràfics $(5$ elevacions i 2 depressions), hidrogràfics (7), de la vegetació (3), del litoral (7), de la xarxa viària (3 camins i 8 hostals) i defensius (6). Però fins i tot alguns d'aquests topònims aparentment no agrícoles es relacionen amb el camp: els camins i els hostals eren usats principalment pels pagesos; els ullals podien ser aprofitats per al reg hortícola; i els edificis de defensa protegien la ciutat de València, però també el seu ric espai agrícola.

\subsection{Anàlisi toponimica crítica}

Després d'analitzar el contingut semàntic dels topònims urbans de l'Horta de València estem en disposició de reconstituir virtualment un paisatge cultural desaparegut en gran part. Es tractaria d'un paisatge obert d'horta irrigada (normalment cultius herbacis regats a partir d'un complex sistema hidràulic de sèquies $\mathrm{i}$ assuts) que cap a la muntanya esdevenia secà (amb cultius arboris i arbustius, notablement olivera i vinya); amb poblament concentrat i sobretot dispers —especialment alqueries_-, connectat entre si per sendes i per camins que, al seu torn, comptaven amb hostals; també amb presència de barrancs, salines, ullals, marjals i accidents costaners, així com zones pedregoses i elevades a l'oest i al nord; així mateix amb torres i fortaleses de defensa, i alguna instal.lació portuària (figura 2).

L'enorme desenvolupament urbà a què ens hem referit en la introducció ha provocat la reducció i la marginalització de l'horta de València. El ric patrimoni paisatgístic hortícola ha experimentat una accelerada degradació, mentre que la pressió urbanística només s'ha detingut recentment a causa de la crisi econòmica internacional. Entre les oportunitats que ens ha brindat aquesta crisi trobem que la destrucció de l'horta s'ha aturat i que l'avantprojecte de la nova Llei i Pla d'Acció Territorial (PAT) d'Ordenació i Dinamització de l'Horta (2016) garanteix que no es consumirà en el curt termini més horta per a afavorir el desenvolupament urbà. A més, el ple de les Corts Valencianes de 22 de febrer de 2018 aprovà la llei de l'Horta de València que pretén la preservació i recuperació dels seus valors agraris, ambientals, paisatgístics, culturals 
Figura 2. Reconstitució cartogràfica del paisatge de l'Horta de València a partir dels actuals topònims urbans

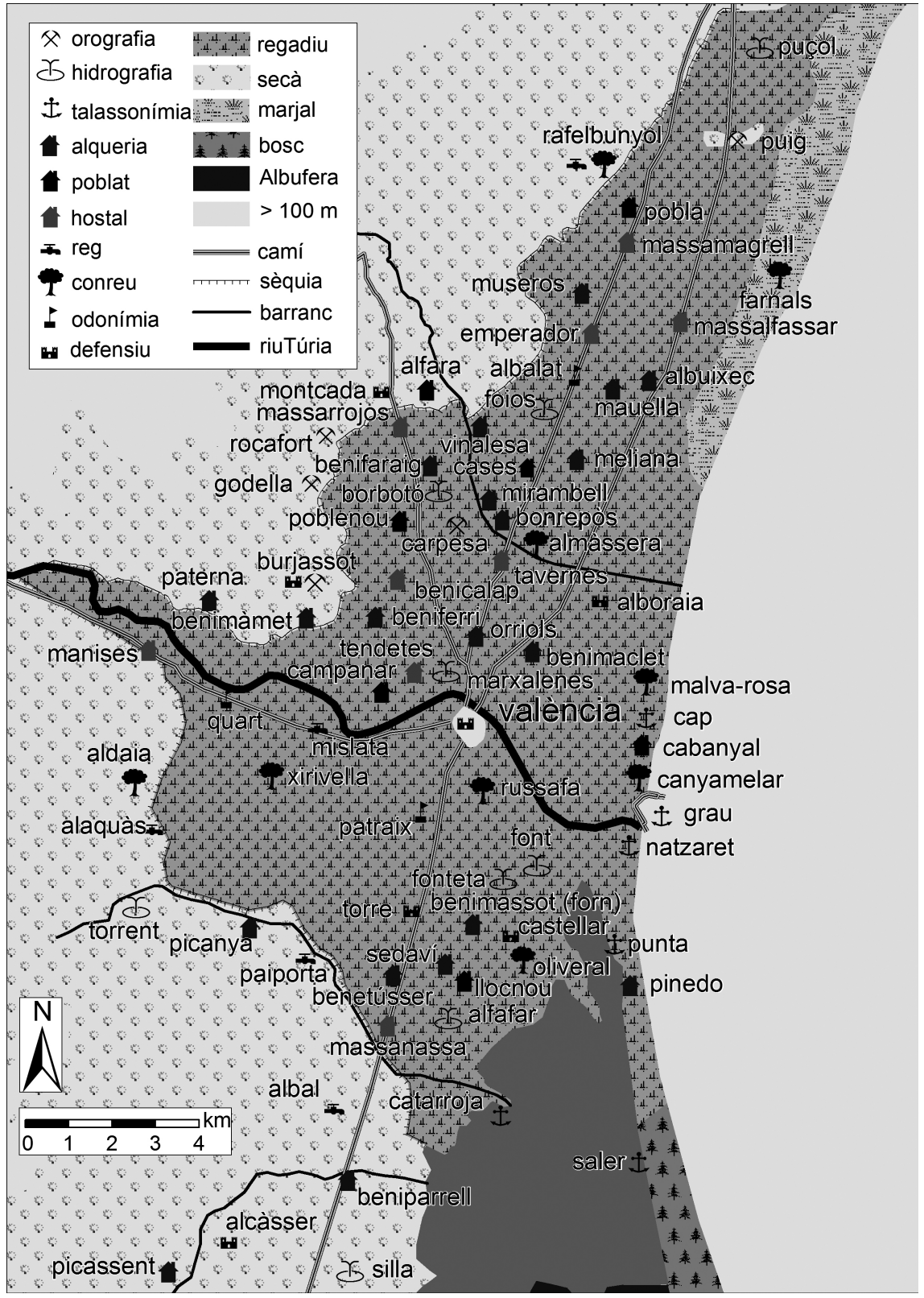

Font: elaboració pròpia 
i històrics. Aquesta llei s'ha pogut aprovar gràcies a la major conscienciació ecològica existent en el nou govern valencià i entre la població en general a l'hora de defensar el paisatge, en tant que element identitari del territori. Amb la difusió entre els ciutadans de l'Horta de l'etimologia dels noms de llocs on viuen, pretenem reforçar encara més aquesta consciència.

L'anàlisi toponímica clàssica ens permet reconstituir un paisatge cultural - lligat a l'aigua - que enclou una enorme riquesa patrimonial. Aquest paisatge forma part de la identitat comarcal i, com a tret identitari, convé revalorar-lo, després de dècades de destrucció i degradació. Aquesta reconstitució permet donar a conèixer a la ciutadania el significat dels topònims urbans principals, per tal que siga conscient que allà on avui es troba el seu habitatge, en el passat hi va haver un paisatge agrari excepcional basat en una tradició mil.lenària d'aprofitament de l'aigua. Es pretén que els urbanites globalitzats i aliens al seu espai local immediat coneguen la riquesa patrimonial que s'oculta darrere de la toponímia dels pobles i ciutats en què resideixen, i que valoren allò que encara resta d'aquest paisatge hortícola.

\section{Discussió. Integració de les anàlisis toponímiques clàssica i crítica}

En aquest article combinem els enfocaments clàssic i crític de l'anàlisi toponímica. D'una banda analitzem l'etimologia dels topònims, i de l'altra estudiem el paper d'aquests mateixos topònims des del punt de vista socioespacial i identitari. Sota estructures de poder (colonial, autoritari o d'altra mena) que pretenen justificar-se dins el territori és molt evident el paper ideològic $\mathrm{i}$ identitari de la toponímia. No ho és tant en el cas de la toponímia medieval pragmàtica —allunyada d'estructures de poder fortes i jerarquitzades-que aparentment es limita a descriure els elements que componen un paisatge. No obstant això, considerem que cap topònim no és asèptic: tots es creen dins d'un context social, cultural i econòmic determinat, i en porten l'empremta. En el cas de l'Horta de València, el fet que la majoria dels noms dels pobles tinguen un origen lligat a l'agricultura s'explica perquè la societat i l'economia d'aquell territori depengué durant molts segles de la riquesa agrària. Són pocs els topònims dels pobles de l'Horta que no estan lligats a l'agricultura, $i$ aquests topònims no agraris solen respondre al principi d'excepcionalitat descrit per Joan Tort (2003), segons el qual alguns noms de lloc tendeixen a reflectir les caracteristiques excepcionals del medi, més que no pas les típiques. Així, trobem a l'Horta topònims urbans que duen el nom d'una muntanya, d'un torrent o d'una fortalesa, perquè es volia fer notar l'excepcionalitat d'aquell lloc.

En la societat actual, en què molts espais agraris periurbans han deixat de ser funcionals, la toponímia, derivada d'un procés socioespacial dinàmic, ha perdut el sentit originari. Amb aquest article, però, pretenem donar-li una nova significació: a partir de la difusió entre la ciutadania de l'origen toponímic dels noms dels pobles on viu, pretenem crear un lligam històric que servisca de vincle afectiu i identitari amb el present. 


\section{Consideracions finals. Plausibilitat de l'anàlisi toponímica}

El propòsit d'aquest article és l'anàlisi complexa dels topònims urbans d'una regió mediterrània — com ara l'Horta de València—, caracteritzada per un predomini agrícola del regadiu al llarg de la història. Aquest tipus d'anàlisi complexa pot extrapolar-se a altres regions mediterrànies (com ara el Pla de Llobregat, la Vega del Segura, la ribera del riu Tíber, la plana campana napolitana o la Conca d'Oro palermitana) o, fins i tot, a qualsevol regió urbana europea d'antic predomini agrícola. Aquella riquesa agrària és responsable de l'actual desenvolupament urbà, que deriva de l'acumulació de capital agrícola reinvertit en activitats més rendibles, de tipus industrial, comercial o de serveis. Al capdavall, aquesta inversió en altres activitats més rendibles és també responsable de la pròpia degradació i desaparició de l'horta. El ric i fecund paisatge cultural hortícola propi de les planes mediterrànies és avui només una ombra del que fou en un passat no gaire llunyà. No tot el paisatge hortícola ha desaparegut, però allà on sí que ho ha fet (als nuclis urbans, fonamentalment), només queda alguna romanalla ací $\mathrm{i}$ allà de l'excepcional sistema hidràulic que permetia el reg a les fertils terres d'horta mediterrània. El que sí que se n'ha preservat de manera quasi intacta ha estat la toponímia. L'estudi dels noms de lloc que hem dut a terme en aquest article ens ha permès fer reviscolar un paisatge cultural desaparegut en gran part i pretenem, alhora, que servisca per a conscienciar la població del valor d'allò que resta encara d'aquest paisatge.

A partir de l'enfocament clàssic de recol-lecció i estudi de noms de lloc (urbans) desencriptem els topònims de llocs urbans per a arribar a uns resultats que confirmen el predomini històric d'una toponímia - i, per tant, d'un paisatge - agrícola que implica una enorme riquesa patrimonial. Tot seguit, des d'una perspectiva ideològica, donem a conèixer a la ciutadania aquest paisatge cultural, per tal que siga sabedora que allà on hi ha actualment els seus habitatges, en el passat hi havia un paisatge agrari excepcional del qual resta avui poca cosa més que la toponímia. Aquest paisatge, amb els topònims corresponents, forma part de la identitat comarcal i, en tant que tret identitari, convé revalorar-lo, després de dècades de destrucció, degradació i abandó.

La combinació entre l'enfocament clàssic de catalogació de topònims i l'enfocament crític que incideix en el context socioespacial permet una anàlisi toponímica més exhaustiva: d'una banda, possibilita la reconstrucció del paisatge agrari; de l'altra, situa la creació dels topònims en un context històric de clar predomini econòmic agrícola. Aquesta anàlisi dota la toponímia d'utilitat en l'actualitat, ja que en ser difosa entre una ciutadania cada volta més conscienciada de la necessitat de preservar els paisatges culturals, crea uns vincles identitaris - és a dir, estableix un lligam afectiu entre la toponímia d'un territori i la ciutadania que l'habita— que permeten revalorar el paisatge agrari que encara sobreviu. 


\section{Referències bibliogràfiques}

AlCañIz, Mercedes (ed.) (1987). Pobles del Sud. València: Ajuntament.

Alderman, Derek H. (2008). «Place, naming, and the interpretation of cultural landscapes». A: B. Graham i P. Howard (ed.). The Ashgate research companion to heritage and identity. Aldershot: Ashgate, 195-213.

AldERMAN, Derek H. i INWOOD, Joshua (2013). «Street naming and the politics of belonging: spatial injustices in the toponymic commemoration of Martin Luther King, Jr.». Social and Cultural Geography, 14 (2), 211-33. <http://dx.doi.org/10.1080/14649365.2012.754488>

AlgeO, John i AlgeO, Katie (2000). «Onomastics as an interdisciplinary study». Names, 48 (3-4), 265-274. <http://dx.doi.org/10.1179/nam.2000.48.3-4.265>

BERG, Lawrence D. i KEARNS, Robin A. (1996). «Naming as norming: 'race', gender, and the identity politics of naming places in Aotearoa/New Zealand». Environment and Planning D: Society and Space, 14, 99-122.

BARCElÓ, Carme (2010). Noms aràbics de lloc. València: IIFV-Bromera.

Bourdieu, Pierre (1991). Language and Symbolic Power. Cambridge: Harvard University Press.

Carmona, Pilar (2002). "Geomorfología de la llanura de Valencia: el río y la ciudad». A: Historia de la ciudad. II. Territorio, sociedad y patrimonio: una visión arquitectónica de la historia de la ciudad de Valencia. València: Col-legi Oficial d'Arquitectes de la Comunitat Valenciana, Col-legi Territorial d'Arquitectes de València, 17-27.

Casanova, Emili (2011). «Comunidad Valenciana». A: Toponimia hispánica. Origen y evolución de nuestros topónimos más importantes. València: Denes, 257-292.

CONSEll D'Europa (2000). Conveni europeu del paisatge. Florència. Barcelona: Departament de Medi Ambient, Generalitat de Catalunya. <http:/www.gencat.cat/ mediamb/publicacions/monografies/conveni_europeu_paisatge.pdf $>$.

Corbín, José Luis (1995). Ruzafa: la bien plantada. València: Federico Doménech.

COROMINES, Joan (1965). "Introducció a l'estudi de la toponímia catalana». Estudis de Toponimia Catalana, I. Barcelona: Barcino, 3-70.

- (1989-1997). Onomasticon Cataloniae. Els noms de lloc i noms de persona de totes les terres de llengua catalana. Barcelona: Curial Edicions Catalanes i La Caixa, 8 vol.

Corriente, Federico (ed.) (2008). Dictionary of Arabic and allied loanwords. Spanish, Portuguese, Catalan, Galician and kindred dialects. Leiden-Boston: Brill Academic Pub.

DAUZAT, Albert (1971). La toponymie française. París: Payot.

DaVidson, Joyce; Bond, Liz i SMITH, Mick (ed.) (2005). Emotional geographies. Aldershot: Ashgate.

Di Giminiani, Piergiorgio i FONCK, Martín (2015). «El paisaje como proceso de vida: experiencias de domesticación del bosque en el sur de Chile». Revista de Geografía Norte Grande, 61, 7-24. <http://dx.doi.org/10.4067/S0718-34022015000200002>

DiÉGuEZ, Maria Àngels (1998). «Topònims esmentats al Llibre de Cort de Justícia de València (1279-1321)», Actes del XXIV Col-loqui de la Societat d'Onomàstica. Eivissa, 106-118.

DomíngueZ, Martí (2014). "Una escassa collita. Valors culturals de l'horta». A: La Universitat de València i els seus entorns: L'Horta de València. València: Universitat de València, 68-71. 
DORION, Henri (1984). «Les relations entre la toponymie et les autres sciences sociales». A: 450 ans de noms de lieux français en Amerique du Nord. Québec: Les Publicacions du Québec, 103-108.

FUCHS, Stephan (2015). «History and heritage of two Midwestern towns: a toponymic-material approach». Journal of Historical Geography, 48, 11-25. <http://dx.doi.org/10.1016/j.jhg.2015.01.003>

Georgiou, Vasiliki (2010). "Competing discourses in the debate on place names in Cyprus». Journal of Language \& Politics, 9 (1), 140-164. <http://dx.doi.org/10.1075/jlp.9.1.07geo>

Gil OlCinA, Antonio (2013). Singularidades del régimen señorial valenciano. Alacant: Universitat d'Alacant.

GÓMEZ-MENDOZA, Josefina (2013). «Del patrimonio paisaje a los paisajes patrimonio». Documents d'Anàlisi Geogràfica, 59 (1), 5-20. <https://doi.org/10.5565/rev/dag.48>

Grimalt, Miquel; Ordinas, Antoni i CALDENTEY, Joan (2009). «El paisatge vegetal de Menorca a través de la fitotoponímia». Documents d'Anàlisi Geogràfica, 55, 93-116.

Higueras, Ester (2009). Paisaje y territorio, vol. 2. Madrid: Instituto Juan de Herrera. IRANZO, Emilio (2009). El paisaje como patrimonio rural: propuesta de una sistemática integrada para el análisis de los paisajes valencianos. Tesi de doctorat. Universitat de València.

- (2014). «La Huerta de Valencia. Incertidumbre para un paisaje cultural ancestral». A: Fernando Molinero (coord.). Atlas de los paisajes agrarios de España. Madrid: Ministerio de Agricultura, Alimentación y Medio Ambiente, 512-532.

JORDAN, Peter (2012). "Place names as ingredients of space-related identity». Names and Identities, 4 (2), 117-131. <https://www.journals.uio.no/index.php/osla/article/view/314>

Kearns, Robin A. i Berg, Lawrence D. (2002). «Proclaiming place: towards a geography of place name pronunciation». Social and Cultural Geography, 3, 283-302. <http://dx.doi.org/10.1080/1464936022000003532>

KEARNEY, Amanda i Bradley, John J. (2009). «Too strong to ever not be there': place names and emotional geographies». Social and Cultural Geography, 10, 77-94. <http://dx.doi.org/10.1080/14649360802553210>

Light, Duncan i YounG, Craig (2015). «Toponymy as commodity: exploring the economic dimensions of urban place names». International Journal of Urban and Regional Research, 39 (3), 435-450. <https://doi.org/10.1111/1468-2427.12153>

MATA, Rafael (2008). «El paisaje, patrimonio y recurso para el desarrollo territorial sostenible: conocimiento y acción pública». Arbor, 184 (729), 155-172. <http://dx.doi.org/10.3989/arbor.2008.i729.168>

- (2014). «Paisajes para un desarrollo sustentable y participativo». Urbano, 17 (30), 8-21.

Membrado-Tena, Joan Carles (2012). «Identity Conflict un the Land of València during the Post-Franco Democratic Period». Saitabi, 62-63, 187-210. <https:// ojs.uv.es/index.php/saitabi/article/view/3861>

- (2014). "An Analysis of Toponymic Anomalies in Valencian Municipalities by Means of a GIS». Proceedings of the XXIV ICOS International Congress of Onomastic Sciences, 2621-2641.

<http://dx.doi.org/10.2436/15.8040.01.255> 
- (2015a). «Migración residencial y urbanismo expansivo en el mediterráneo español». Cuadernos de Turismo, 35, 259-285. <http://dx.doi.org/10.6018/turismo.35.221611>

- (2015b). «Uso del LIDAR para verificar la semántica de topónimos de relieve irrelevantes». A: J. De La Riva; P. Ibarra; R. Montorio i M. Rodrigues (ed.). Análisis espacial y representación geográfica: innovación y aplicación. Saragossa: Universidad de Zaragoza-AGE, 749-758. <http://congresoage.unizar.es/eBook/>

- (2016). «Entes territoriales de escala comarcal en la Administración local española». Documents d'Anàlisi Geogràfica, 62 (2), 347-371.

<http://dx.doi.org/10.5565/rev/dag.300>

Mitchelson, Matthew L.; Alderman, Derek H. i Popke, E. Jeffrey (2007). «Branded: the economic geographies of MLK streets». Social Science Quarterly, 88, $120-45$. <http://dx.doi.org/10.1111/j.1540-6237.2007.00450.x>

Moreu-Rey, Enric (1995). "Tipologia toponímica». A: Vicenç Rosselló i Emili Casanova (ed.). Materials de Toponímia, I. València: Generalitat Valenciana Universitat de València, 45-52.

NoguÉ, Joan (2007). «Territorios sin discurso, paisajes sin imaginario: retos y dilemas». Eria, 73-74, 373-382. <http://www.unioviedo.es/reunido/index.php/RCG/ article/view/1593/1508>

Nogué, Joan i De SAN Eugenio, Jordi (2009). «Pensamiento geográfico versus teoría de la comunicación. Hacia un modelo de análisis comunicativo del paisaje». Documents d'Anàlisi Geogràfica, 55, 27-55.

- (2011). «La dimensión comunicativa del paisaje: una propuesta teórica y aplicada». Revista de Geografía Norte Grande, 49, 25-43.

<http://dx.doi.org/10.4067/S0718-34022011000200003>

Poirier, Jean (1965). Toponymie. Méthode d'enquête. Québec: Les Presses de l'Université Laval.

Querol, Ernest (1995). «La metodologia en els estudis de toponímia». A: Vicenç RosSElló i Emili Casanova (eds.). Materials de Toponímia, I. València: Generalitat Valenciana - Universitat de València, 61-74.

RaEnTO, Pauliina i Douglass, William A. (2001). "The naming of gaming». Names, 49, $1-35$.

<https://doi.org/10.1179/nam.2001.49.1.1>

RAPER, Peter E. (2011). Interpretations and translations of Bushman (San) place-names. Acta Varia (2). Bloemfontein: Sun Media, 2011.

RiBES, Enric (2005). La supervivència de la toponimia precatalana d'Eivissa i Formentera. Barcelona: Publicacions de l'Abadia de Montserrat.

RiEsCO, Pascual (2010). «Nombres en el paisaje: la toponimia, fuente de conocimiento y aprecio del territorio». Cuadernos Geográficos, 46, 7-34. <http://revistaseug.ugr. es/index.php/cuadgeo/article/view/629/716>

ROSE-REDWOOD, Reuben (2008). «From number to name: symbolic capital, places of memory, and the politics of street renaming in New York City». Social and Cultural Geography, 9, 431-52. <http://dx.doi.org/10.1080/14649360802032702>

Rose-Redwood, Reuben; Alderman, Derek H. i Azaryahu, Maoz (2010). «Geographies of toponymic inscription: new directions in critical place-name studies». Progress in Human Geography, 34 (4), 453-470.

<https://doi.org/10.1177/0309132509351042> 
Rosselló, Vicenç (1987). "Les salines de l'Albufera: un enigma històric i una hipòtesi geogràfica». Cuadernos de Geografía, 42, 113-132.

- (2004). Toponimia, geografia i cartografia. València: Universitat de València.

SALICRÚ, Roser (1995). El tràfic de mercaderies a Barcelona segons els comptes de la lleuda de Mediona (febrer de 1434), I. Barcelona: CSIC (Milà i Fontanals).

SANCHIS IBOR, Carles (2000). "Notes sobre la toponímia i l'evolució del paisatge a l'Albufera de València». A: Emili CASANOVA (ed.). Estudis de toponimia valenciana. València: Denes, 431-444.

SAnCHIS Pallarés, Antonio (2009). Historia del Cabanyal. Poble Nou de la Mar (12381897). València: L'Oronella.

- (2012). Historia de la Malvarrosa. Nacida del Agua. València: Germania.

SAUER, Carl Ortwin (1956). «The education of a geographer». Annals of the Association of American Geographers, 46, 287-299. <http://dx.doi.org/10.1111/j.1467-8306.1956.tb01510.x>

Segura Munguia, Santiago (2014). Lexicón etimológico y semántico del latín y de las voces actuales que proceden de raíces latinas o griegas. Bilbao: Universidad de Deusto.

STEENKAMP, Joan-Marié (2015). A toponymical study of place name heritage in Mossel Bay (Western Cape). Tesi de doctorat. University of the Free State.

TeIXIDOR, M. Jesús (2004). "Riu i carrera. Actuacions de la 'Fàbrica Nova' a la València del segle XVIII». A: Vicenç Rosselló (ed.). Historia, clima y paisaje. Estudios geográficos en memoria del profesor Antonio López Gómez. València: Universitat de València, 217-232.

TERRADO, Xavier (1994). «Fonaments per a l'estudi etimològic de la toponímia catalana». A: Albert Turull (ed.). Introducció a l'onomàstica. Lleida: Institut d'Estudis Ilerdencs.

- (2007). «Cano González, Ana María / Germain, Jean / Kremer, Dieter (ed.) (2004). Dictionnaire historique de l'anthroponymie romane Patronymica Romanica (Patrom). Volume II/1: L'home et les parties du corps humain (première partie). Tübingen: Max». Estudis Romànics, 29, 381-386.

TESSER, Claudio (2000). «Algunas reflexiones sobre los significados del paisaje para la Geografía». Revista de Geografia Norte Grande, 27, 19-26.

Thornton, Thomas F. (1997). "Anthropological studies of Native American place naming». American Indian Quarterly, 21, 209-228.

TORT, Joan (2000). «Toponimia y territorio. Los nombres de los núcleos de población de la comarca del Baix Camp, Tarragona, desde una perspectiva onomasiológica». Scripta Nova, 67. <http://www.ub.edu/geocrit/sn-67.htm>

- (2001). "La toponímia com a camp de coneixement interdisciplinari. Algunes bases teòriques i epistemològiques per a l'estudi dels noms de lloc». Scripta Nova, 86. <http://www.ub.edu/geocrit/sn-86.htm>

- (2003). «Toponimia y marginalidad geográfica. Los nombres de lugar como reflejo de una interpretación del espacio». Scripta Nova, VII, 138. <http://www.ub.edu/ geocrit/sn/sn-138.htm>

TORT, Joan i SANCHO, Alexis (2014). «Toponyms as 'landscape indicators'». A: Proceedings of the XXIV ICOS International Congress of Onomastic Sciences, 1987-2016. <http://dx.doi.org/10.2436/15.8040.01.200>

WHATMORE, Sarah (2002). Hybrid geographies: natures, cultures, spaces. Londres: Sage. Withers, Charles W. J. (2000). «Authorizing landscape: 'authority', naming and the Ordenance Survey's mapping of the Scottish Highlands in the nineteenth century». Journal of Historical Geography, 26, 532-54. <http://dx.doi.org/10.1006/jhge.2000.0244> 
ZELINSKY, W. (1997). «Along the frontiers of name geography». Professional Geographer, 49, 465-466.

ZubelZU, Sergio i AlLENDE, Fernando (2015). «El concepto de paisaje y sus elementos constituyentes: requisitos para la adecuada gestión del recurso y adaptación de los instrumentos legales en España». Cuadernos de Geografia. Revista Colombiana de Geografia, 24, 29-42.

$<$ http://dx.doi.org/10.15446/rcdg.v24n1.41369> 